\title{
Prevalence and family risk of ulcerative colitis and Crohn's disease: an epidemiological study among Europeans and South Asians in Leicestershire
}

Leicester General Hospital and University of Leicester J R Thompson A C B Wicks

J F Mayberry

Bristol Royal Infirmary and University of Bristol C S J Probert

\section{Department of} Epidemiology and Public Health Medicine, University of Bristol A O Hughes

Correspondence to: Dr C S J Probert, Department of Medicine, Gloucestershire Royal Hospital, Great Western Road, Gloucester GL1 3NN.

Accepted for publication 10 March 1993

\author{
C S J Probert, V Jayanthi, A O Hughes, J R Thompson, A C B Wicks, J F Mayberry
}

\begin{abstract}
The family history of patients identified during incidence studies in Leicestershire were investigated and the prevalence and comparative risks calculated; 1254 patients aged 15 to 80 years were sent a questionnaire about their family history. All cases with a positive family history were reviewed and confirmed cases included in the study. In Europeans the standardised prevalence of Crohn's disease was $75 \cdot 8 / 10^{5}$ and that of ulcerative colitis $90 \cdot 8 / 10^{5}$. The prevalence of Crohn's disease among South Asians was $33 \cdot 2 / 10^{5}$ and that of ulcerative colitis 135/105. The prevalence of Crohn's disease in Europeans was significantly greater than that in Hindus $\left(\chi^{2}=16, p<0.001\right)$, while the prevalence of ulcerative colitis was significantly lower in Europeans than Hindus $\left(\chi^{2}=27\right.$, $\mathbf{p}<0.001)$ and Sikhs $\left(\chi^{2}=4.4, p<0.05\right)$. The comparative risk of developing ulcerative colitis in first degree relatives of Europeans patients with ulcerative colitis was increased by approximately 15, but the risk of Crohn's disease was not increased. The comparative risk of developing Crohn's disease among first degree relatives of patients with Crohn's disease was increased by up to 35 , the comparative risk of ulcerative colitis was approximately 3. The risk among relatives of South Asian patients with Crohn's disease was not increased, but the risk of ulcerative colitis to relatives of patients with ulcerative colitis was. This study supports the view that Crohn's disease and ulcerative colitis arise in people with a genetic predisposition and exposed to some, as yet unknown, environmental factor. (Gut 1993; 34: 1547-1551)
\end{abstract}

Ulcerative colitis and Crohn's disease are chronic conditions of unknown cause. They may lead to lifelong ill health, often requiring drugs and sometimes surgery. Patients are anxious about the diagnosis and often fear they might pass the condition onto their offspring. Earlier studies ${ }^{1-8}$ have shown that the risk of developing inflammatory bowel disease is increased in first degree relatives.

Leicestershire comprises the city and seven market towns in a large agricultural area. It is served by one health authority. The country has a population of approximately 930000 , of whom 93000 are South Asian. 'South Asian' refers to people whose families originate from India, Pakistan, or Bangladesh. ${ }^{10}$ The city of Leicester has comparatively more South Asians than the rural areas, indeed $81 \%$ of South Asians in the county live within the city boundary." Thus, nearly $8 \%$ of the 1.2 million South Asians in Britain live in Leicestershire. ${ }^{12}$

The aim of this study was to investigate the comparative risk and prevalence of ulcerative colitis and Crohn's disease among relatives of patients on the community based register in Leicestershire. This would help to better advise patients about the familial risk and further assess the role of heredity as a aetiological factor in Europeans and South Asians.

\section{Method}

Both the incidence and mortality among patients with ulcerative colitis and Crohn's disease in Leicestershire have been reported. ${ }^{13-16}$ The diagnosis of Crohn's disease or ulcerative colitis had been made on the basis of internationally accepted criteria. ${ }^{17}$ Patients aged 15 to 80 years, who were resident in Leicestershire, were included in the study. Fifteen children aged less than 15 years were excluded from the calculations. Patients were sent a questionnaire about their family. The details collected included any history of ulcerative colitis or Crohn's disease among parents, siblings or offspring. The age of relatives was not collected, but the number of siblings and the birth position of the propositus were recorded. The patient's total number of offspring and the number aged over 15 years were noted. Patients who did not reply were sent a second and, if necessary, third questionnaire.

Propositi were asked to give the name and address of their affected relatives. The whereabouts of unaffected relatives was not determined, although we realise that some relatives of South Asians reside overseas. Each positive family history was investigated and the diagnosis of Crohn's disease or ulcerative colitis confirmed or refuted from the relative's own case notes. The same diagnostic criteria were applied as had been used in the incidence studies.

The prevalences of ulcerative colitis and Crohn's disease in Leicestershire were found from the community based register taking into account patients who had died or moved away from the county. The prevalence was standardised to the population of Leicestershire for each ethnic group.

In the calculation of comparative risk no subject must contribute twice to the two by two table; for this reason, the prevalence of inflammatory bowel disease amongst first degree relatives was compared with that of Cardiff,' for Crohn's disease, and North Tees ${ }^{18}$ for ulcerative colitis. For South Asians the prevalence reported from Bradford ${ }^{19}$ was used for comparison, even though the population is not strictly comparable 
TABLE I Standardised prevalence of inflammatory bowel disease in Leicestershire

\begin{tabular}{llll}
\hline & \multicolumn{3}{l}{ Prevalence (cases) } \\
\cline { 2 - 4 } Ethnic group & $\begin{array}{l}\text { Crohn's } \\
\text { disease }\end{array}$ & $\begin{array}{l}\text { Ulcerative colitis } \\
\text { (excluding } \\
\text { proctitis) }\end{array}$ & Proctitis \\
\hline European & $75 \cdot 8(645)$ & $90 \cdot 8(754)$ & $37 \cdot 0(302)$ \\
South Asians & $33 \cdot 2(31)$ & $136 \cdot 0(134)$ & $37 \cdot 5(40)$ \\
South Asian subgroups & & & \\
$\quad$ Hindus & $31 \cdot 9(20)$ & $151 \cdot 5(98)$ & $41 \cdot 5(27)$ \\
$\quad$ Sikhs & $30 \cdot 8(4)$ & $138 \cdot 4(19)$ & $69 \cdot 2(9)$ \\
Moslems & $53 \cdot 8(7)$ & $107.6(17)$ & $23.0(4)$ \\
\hline
\end{tabular}

Europeans had significantly more Crohn's disease than Hindus and significantly less ulcerative colitis than either Hindus or Sikhs. Prevalence: cases $/ 100000$.

with that of Leicester, because there was no alternative. The prevalence in each generation was compared with the 'control' population. The prevalence in each generation, however, could not be standardised because the age of the nonaffected relatives was not known. The data for siblings, however, were set against the background of knowing the birth position of the propositus. Confidence intervals for the prevalence values were calculated using a standard method. ${ }^{20}$ Comparative risk confidence intervals were found using the method described by Katz et $a l^{21}$ using Confidence Interval Analysis software, ${ }^{22}$ except where the value was zero when the method described by Bailey ${ }^{23}$ was used.

Multiple ascertainment of kindreds can confound studies of family risk. Only one subject per kindred may be attributed propositus state. The decision who this should be is arbitrary and can be approached in two ways, which, in practice, have the same result; either arbitrary assignment or 'shared' assignment with each affected individual contributing. The latter was adopted; thus data from a kindred with two potentially equally valid propositi (index patients sent questionnaires) were both included in the analysis in both ways, with weights of 0.5 assigned to each part of the data. Where three index patients belonged to one kindred an equivalent adjustment was made. In this way each subject did not contribute to the calculations more than once.

\section{Results}

PREVALENCE

The prevalence of Crohn's disease and ulcerative colitis on 31 December 1989 was calculated from data obtained during the incidence and mortality studies. ${ }^{13-16}$ On 1 January 1990 there were 676 patients with Crohn's disease, of whom 645 were European and 31 South Asian. Eight hundred and eighty eight people had ulcerative colitis, excluding disease limited to the rectum (proctitis); 754 were European and 134 South Asian.

In Europeans, the standardised prevalence of ulcerative colitis was $90 \cdot 8 / 10^{5}(95 \%$ CI 84 to 97$)$ and that of Crohn's disease $75 \cdot 8 / 10^{5}$ (95\% CI 70 to 83) (Table I). Among South Asians, the standardised prevalence of ulcerative colitis, excluding proctitis, was $136 / 10^{5}$ (95\% CI 111 to $161)$ and that of Crohn's disease $33 \cdot 2 / 10^{5}(95 \% \mathrm{CI}$ 23 to 46). The highest prevalence for ulcerative colitis was amongst Hindus $\left(152\right.$ cases $\left./ 10^{5}\right)$ while the highest value for proctitis $\left(41 \cdot 5 / 10^{5}\right)$ was amongst Sikhs. The prevalence of ulcerative colitis was significantly lower in Europeans than that in Hindus (95\% CI of difference 34.6 to $97 \cdot 8$ per $\left.10^{5}, \chi^{2}=27, \mathrm{p}<0.001\right)$ and Sikhs $(95 \% \mathrm{CI}$ of difference 9 to 122 per $\left.10^{5}, \chi^{2}=4.4, p<0.05\right)$. When other comparisons of the prevalence of ulcerative colitis were made between ethnic groups no significant difference was found. The prevalence of Crohn's disease was highest in Europeans. The prevalence of Crohn's disease in Europeans was significantly greater than that in Hindus (95\% CI of difference 30 to 60.4 per $10^{5}$, $\left.\chi^{2}=16, p<0.001\right)$. Again no other comparison of prevalence was significant.

\section{CROHN'SDISEASE PATIENTS}

Four hundred and twenty four (90\%) Europeans and $18(75 \%)$ South Asian patients replied to the questionnaire. Table II summarises the results. Among Europeans, 49 patients with Crohn's disease reported 54 relatives with inflammatory bowel disease. The diagnosis was confirmed in 44, of whom four had ulcerative colitis. Of the remainder, most had irritable bowel syndrome although two had colorectal cancer. Four had died and no notes could be obtained, and one chose not to take part in the study. The prevalence of Crohn's disease of $1931 / 10^{5}$ (95\% CI 1071 to 2791) among siblings. The prevalence of ulcerative colitis was $302 / 10^{5}$ (95\% CI -30 to 649) among siblings. The comparative risk (CR) of developing Crohn's disease was substantially increased among first degree relatives, especially for siblings (CR $=35,95 \%$ CI 21.6 to $55 \cdot 6)$ and offspring over $15(\mathrm{CR}=29 \cdot 1,95 \% \mathrm{CI} 14 \cdot 4$ to 59$)$. None of the patients was married to each other. The risk of developing ulcerative colitis among first degree relatives of Crohn's disease patients was increased marginally with wide confidence intervals (Table II).

Only one South Asian gave a family history of Crohn's disease, but unfortunately this could not be confirmed because of the availability of clinical notes (Table III). Less than one case, however, would be expected. The three categories of first degree relatives were combined for analysis because of the small numbers.

In Europeans, the average family size was 3.4 offspring and the mean position of the propositus was $2 \cdot 1$. Among South Asians, the mean family size was $5 \cdot 1$ offspring and the mean position of the propositus was $3 \cdot 2$. Thus, in both ethnic groups the propositus was, on average, the middle born, suggesting that the prevalence is likely to be representative, although possibly the magnitude of the risk may be underestimated. In one kindred all three members had Crohn's disease.

Most of the affected relatives lived in Leicestershire. One patient's father, with Crohn's disease, however, lived in Lancashire and three patients had affected siblings who lived outside Leicestershire (one in London, one in Scotland, and one in Cornwall). For each of these patients extracts of their notes were obtained. 
TABLE II Prevalence and comparative risk of ulcerative colitis and Crohn's disease in first degree relatives of Europeans with inflammatory bowel disease

\begin{tabular}{|c|c|c|c|c|c|c|}
\hline & \multicolumn{3}{|c|}{ Relative of patient with ulcerative colitis } & \multicolumn{3}{|c|}{ Relative of patient with Crohn's disease } \\
\hline & Parent & Sibling & $\begin{array}{l}\text { Offspring } \\
(>15 y)\end{array}$ & Parent & Sibling & $\begin{array}{l}\text { Offspring } \\
(>15 y)\end{array}$ \\
\hline \multirow{11}{*}{$\begin{array}{l}\text { No at risk } \\
\text { No of cases of ulcerative colitis } \\
\text { Prevalence of ulcerative colitis } \\
\text { (cases/100) } \\
95 \% \text { CI } \\
\text { Comparative risk of ulcerative } \\
\text { colitis } \\
95 \% \text { CI } \\
\text { No of cases of Crohn's disease } \\
\text { Prevalence of Crohn's disease } \\
\text { (cases/100) } \\
95 \% \text { CI } \\
\text { Comparative risk of Crohn's } \\
\text { disease (cases } / 100 \text { ) } \\
95 \% \text { CI }\end{array}$} & 917 & 1094 & 594 & 825 & 984 & 493 \\
\hline & 12 & 11 & 6 & 9 & 3 & 1 \\
\hline & $1 \cdot 31 \%$ & $1 \cdot 0 \%$ & $1 \cdot 0 \%$ & 0 & $0 \cdot 3 \%$ & $0 \cdot 2 \%$ \\
\hline & 0.6 to 2.0 & 0.4 to 1.6 & 0.2 to 1.8 & 0 to 0.45 & 0 to 0.65 & 0 to 0.6 \\
\hline & $19 \cdot 2$ & $14 \cdot 6$ & $14 \cdot 8$ & & $4 \cdot 5$ & $3 \cdot 0$ \\
\hline & $10 \cdot 7$ to 34.5 & 7.9 to 26.9 & 6.6 to 33.4 & 0 to 6.4 & 1.4 to $14 \cdot 0$ & 0.4 to $21 \cdot 2$ \\
\hline & & & & & 19 & \\
\hline & $0 \cdot 1$ & 0.09 & $0 \cdot 17$ & 0.9 & $2 \cdot 0$ & $1 \cdot 6$ \\
\hline & 0 to $0 \cdot 3$ & 0.08 to 0.27 & 0 to 0.5 & 0.3 to 1.6 & $1 \cdot 1$ to $2 \cdot 8$ & 0.5 to $2 \cdot 7$ \\
\hline & & $1 \cdot 6$ & & $17 \cdot 4$ & $34 \cdot 7$ & $29 \cdot 1$ \\
\hline & 0.3 to $14 \cdot 0$ & 0.3 to $11 \cdot 7$ & 0.4 to 21.6 & $8 \cdot 6$ to $35 \cdot 3$ & $21 \cdot 6$ to $35 \cdot 6$ & $14 \cdot 4$ to $59 \cdot 0$ \\
\hline
\end{tabular}

The risk of developing ulcerative colitis is considerably increased in relatives of patients with ulcerative colitis, the risk of Crohn's disease is mildly increased. The risk of developing Crohn's disease is considerably increased in relatives of patients with Crohn's disease is mildly increased. The risk of developing
disease, while the risk of ulcerative colitis is small.

rate $=72 \%)$ and 57 (response rate $=57 \%$ ) of South Asians replied. Tables II and III show the prevalence and comparative risk among first degree family members. Among Europeans, 35 patients with ulcerative colitis reported 36 relatives with inflammatory bowel disease. The diagnosis was confirmed in 32, of whom three had Crohn's disease, giving a prevalence of ulcerative colitis of $1308 / 10^{5}$ (95\% CI 573 to 2044 ) among parents and $1005 / 10^{5}$ (95\% CI 414 to 1597) amongst siblings. The comparative risk was significantly increased in Europeans, but not to the extent found in Crohn's disease. The comparative risk was similar in parents $(\mathrm{CR}=19 \cdot 2$, 95\% CI 10.7 to $34 \cdot 5)$, siblings (CR $=14 \cdot 6,95 \%$ CI 7.9 to 26.9 ), and offspring over 15 years $(\mathrm{CR}=14.8 \%$, CI 6.6 to 33.4$)$. The risk of first degree relatives of patients with ulcerative colitis developing Crohn's disease was not increased among 1094 siblings and 594 offspring aged over 15 years.

There was only one confirmed case among relatives of South Asian patients (Table III), although five other cases had been reported. Two were diagnosed and living overseas, one had died and his notes could not be obtained, and in the remaining two cases permission to review clinical notes and specimens was withheld. If all cases had been confirmed the prevalence of ulcerative

TABLE III Prevalence and comparative risk of ulcerative colitis and Crohn's disease in first degree relatives of South Asians with inflammatory bowel disease

\begin{tabular}{|c|c|c|}
\hline & $\begin{array}{l}\text { Relative of } \\
\text { patients with } \\
\text { ulcerative colitis }\end{array}$ & $\begin{array}{l}\text { Relative of } \\
\text { patient with } \\
\text { Crohn's disease }\end{array}$ \\
\hline \multirow{9}{*}{$\begin{array}{l}\text { No at risk } \\
\text { No of cases of ulcerative } \\
\text { colitis } \\
\text { Prevalence of ulcerative } \\
\text { colitis (cases/100) } \\
\text { Comparative risk of } \\
\text { ulcerative colitis } \\
95 \% \text { CI } \\
\text { No of cases of Crohn's } \\
\text { disease } \\
\text { Prevalence of Crohn's } \\
\text { disease (cases/100) } \\
\text { Comparative risk of Crohn's } \\
\text { disease (cases/100) } \\
95 \% \text { CI }\end{array}$} & 415 & 120 \\
\hline & 1 & 0 \\
\hline & 0.42 & 0 \\
\hline & $3 \cdot 5$ & 0 \\
\hline & 0.5 to $25 \cdot 7$ & 0 to $45 \cdot 2$ \\
\hline & 0 & 0 \\
\hline & 0 & 0 \\
\hline & 0 & 0 \\
\hline & 0 to $53 \cdot 8$ & 0 to 186 \\
\hline
\end{tabular}

colitis among siblings would have been $2521 / 10^{5}$ (95\% CI 934 to 5400), comparable with that in siblings of European patients with ulcerative colitis. Once again the three categories of first degree relatives were combined for analysis. The comparative risk to relatives of South Asian patients was 3.5 (95\% CI 0.5 to $25 \cdot 7)$.

In Europeans, the mean family size was $3 \cdot 3$ offspring and the mean position of the propositus was $2 \cdot 1$. The mean family size among South Asians was $5 \cdot 2$ offspring and the mean position of the proband was 3. Propositi tended to be the middle born of the family.

Most affected relatives lived in Leicestershire; four patients had affected siblings outside the country, one in Wales, one in Scotland, one in Derby and one in Kettering. One patient's affected parent lived in Nottingham.

\section{Discussion}

This study reports the prevalence of inflammatory bowel disease in Leicestershire and assesses the comparative risk to first degree relatives of patients. Its community based nature averts the inherent selection bias of hospital based series. All people with inflammatory bowel disease aged 15-80 years from a population of approximately 900000 were approached. This design provides a wide spectrum of socioeconomic backgrounds and ethnic states.

TABLE IV Prevalence of inflammatory bowel disease in Europe

\begin{tabular}{|c|c|c|}
\hline \multirow[b]{2}{*}{ Area of study } & \multicolumn{2}{|l|}{ Prevalence $10^{5}$} \\
\hline & Crohn's disease & ${ }^{\star}$ Ulcerative colitis \\
\hline \multicolumn{3}{|l|}{$\begin{array}{l}\text { United Kingdom } \\
\text { Bradford }{ }^{14}\end{array}$} \\
\hline South Asians & 78 & 59 \\
\hline Derby $^{27}$ & 85 & \\
\hline $\begin{array}{l}\text { High Wycombe }{ }^{2^{24}} \\
\text { Leicestershire }^{131}\end{array}$ & & 70 \\
\hline Europeans & 76 & 128 \\
\hline South Asians & 33 & 174 \\
\hline North Tees ${ }^{\text {Ix }}$ & 35 & 99 \\
\hline Nottingham $^{24}$ & $26 \cdot 5$ & \\
\hline Oxford ${ }^{2 x}$ & 9 & 79.9 \\
\hline Denmark ${ }^{2+}$ & 34 & 117 \\
\hline Germany ${ }^{20} \dagger$ & $54 \cdot 6$ & $24 \cdot 8$ \\
\hline
\end{tabular}

The prevalence of inflammatory bowel disease, among Europeans in Leicestershire was comparable with that reported in other Europeans studies. ${ }^{\star}$ including proctitis, texcluding proctitis. 
PREVALENCE OF INFLAMMATORY BOWEL DISEASE The prevalence of Crohn's disease and ulcerative colitis in Europeans is comparable with that in other recent European studies, ${ }^{18-27}$ although the values have increased since studies of the $1960 \mathrm{~s}$ and $1970 \mathrm{~s}^{2829}$ (Table IV). The prevalence of Crohn's disease in South Asians was marginally lower and that of ulcerative colitis much higher than in Findlay's study ${ }^{19}$ and probably reflects the different ethnic groups - in Leicester, predominantly Gujarati Hindus, and in Bradford, mainly Pakistani Moslems. Fellows et al did not report the prevalence among Asians in their study. ${ }^{27}$

\section{COMPARATIVE RISK}

This study has shown that the risk of developing ulcerative colitis in first degree relatives of European patients with ulcerative colitis is increased about 15-fold, but there is no increased risk of developing Crohn's disease. In contrast, relatives of European patients with Crohn's disease are at a 17- to 35-fold risk of Crohn's disease and an increased risk of ulcerative colitis. This suggests that there is no common predisposition and ulcerative colitis and Crohn's disease have a different cause. The risk of Crohn's disease among relatives of South Asian patients with Crohn's disease is not increased whereas the risk of ulcerative colitis is. This probably reflects the low prevalence of Crohn's disease in this ethnic group.

There has been interest in familial aspects of inflammatory bowel disease since the 1960s. ${ }^{50-32}$ There are only a few studies, however, which have measured the risk to first degree relatives. ${ }^{1-38}$ These studies suggest that the risk of developing Crohn's disease may be 30-times greater in siblings than in the general population and the overall risk to first degree relatives is 13 . Such studies do not show a simple Mendelian pattern of inheritance but suggest that the genetic prodisposition may be explained by another model of inheritance. Kuster et $\mathrm{al}^{4}$ have performed complex segregation analysis on the family history of 387 patients with Crohn's disease and they suggested that the condition is due to a recessive gene with incomplete penetrance which may combine with environmental factors to determine disease susceptibility.

Studies from Copenhagen ${ }^{5}$ and Stockholm ${ }^{6}$ have shown that the risk of developing ulcerative colitis among patients' relatives is increased by eight to 15-fold. The prevalence of Crohn's disease, however, is only increased 3.5 times while relatives of patients with Crohn's disease seem to be at eight to 10 times the risk of developing ulcerative colitis. Orholm et $a l^{8}$ showed a 10-fold increase in the risk of first degree relatives of patients with ulcerative colitis developing ulcerative colitis, after standardisation for age. Similarly, the risk of developing Crohn's disease was increased in first degree relatives of patients with Crohn's disease. Although the risk of Crohn's disease was increased in relatives of patients with ulcerative colitis, this was not statistically significant. Based on the Swedish twin registry Tysk et $a l^{7}$ have shown that heredity is a stronger aetiological factor in Crohn's disease than ulcerative colitis. In an early study, Mayberry et al ${ }^{1}$ also found the risk of Crohn's disease was increased in siblings of patients and suggested the risk of ulcerative colitis may also have been increased. If the Leicestershire prevalence values are applied to the Cardiff population they studied, the comparative risk of developing Crohn's disease to siblings was 21 (95\% CI 10 to $44 \cdot 7)$. The comparative risk of developing ulcerative colitis among the first degree relatives of patients with Crohn's disease was parents $7 \cdot 9$ (95\% CI 2 to $31 \cdot 8$ ), siblings $10 \cdot 1$ (95\% CI 3.4 to 27 ), and offspring over 15 years $7 \cdot 3(95 \% 1$ to $51 \cdot 4)$. This analysis of the data supports their suggestion that the risk of developing ulcerative colitis was increased in relatives of patients with Crohn's disease. The risk, however, was less than that for Crohn's disease. These findings are not inconsistent with those we now present although the risk seems greater in the Cardiff series. There are two explanations for this, firstly, the Cardiff series was smaller than ours and, secondly, as they acknowledge, the differentiation between ulcerative colitis and Crohn's colitis may be difficult. The misclassification of one case would have a large influence on the comparative risk when dealing with so few cases.

These findings confirm that first degree relatives of European patients are at substantially increased risk of developing the same form of inflammatory bowel disease, but probably not a different variety. This suggests that Crohn's disease and ulcerative colitis are separate conditions with similar, but different, genetic predispositions. An alternate explanation, however, that the two diseases are the same but there is a familial factor determining transition to Crohn's disease, cannot be ignored. The lack of risk to relatives of South Asian patients with Crohn's disease probably reflects the low prevalence of the disease in the community and, consequently, a small study group. The smaller increased risk in relatives of South Asian patients with ulcerative colitis may reflect the fact that many relatives still live overseas, often in India, where the condition seems less common. This suggests that their colitis may be misdiagnosed as infective diarrhoea or that they are not exposed to the appropriate environmental factor. In Britain, such environmental agents may interact with the genetic predisposition to give a high prevalence among South Asians.

These findings clearly support the view that Crohn's disease and ulcerative colitis arise in people with a specific genetic predisposition and who have been exposed to an environmental factor. Studies of these diseases in migrant communities may identify the environmental factor.

Dr Probert was supported by the Hilden Charitable Trust and Dr Jayanthi by an award from the British Digestive Foundation and thank the hospital staff and general practitioners of . We wish to and surrounding areas who allowed us to study their patients.

1 Mayberry JF, Rhodes J, Newcombe RG. Familial prevalence Mayberry JF, Rhodes $\mathbf{J}$, Newcombe RG. Familial prevalence of inflammatory bowel disease in

2 Weterman IT, Pena AS. Familial incidence of Crohn's disease in The Netherlands and a review of the literature. Gastroenterology 1984; 86: 449-52. 
3 Lashner BA, Evans AP, Kirsner JB, Hanauer SB. Prevalence and incidence of inflammatory bowel disease in family members. Gastroenterology 1986; 91: 1396-400.

4 Küster W, Pascoe L, Purrman J, Funk S, Majewski F. The genetics of Crohn's disease: complex segregation analysis of a family study with 265 patients and 5387 relatives. $A m \mathcal{F} \mathrm{Med}$ Genet 1989; 32: 105-8

5 Binder V, Weeke E, Olsen JH, Anthonisen P, Ruis P. A genetic study of

6 Monsén U, Berglund M, Brostrom O. Prevalence of inflammatory bowel disease amongst relatives of patients with ulcerative colitis. Scand 7 Gastroenterol $1987 ; 22: 214-8$.

7 Tysk C, Lindberg E, Jarnerot G, Floderus-Myrhed B. Ulcerative colitis and Crohn's disease in an unselected population of tive colitis and Crohn's disease in an unselected population of monozygotic and dizygotic twins. A study of

8 Orholm M, Munkholm P, Langholz E, Nielsen OH, Sorensen TIA, Binder V. Familial occurrence of inflammatory bowel disease. N Engl F Med 1991; 324: 84-8.

9 Carey S, Shukur A. A profile of the Bangladeshi community in East London. New Community 1985; 12: 405

10 Ballard R, Ballard C. The Sikhs: The development of South Asian settlements in Britain. In: Watson JL, ed. Betrueen two cultures. Blackwell: Oxford, 1977.

11 Survey of Leicester 1983. Leicester City Council and Leicestershire County Council.

12 Haskey J. The ethnic minority populations of Great Britain: estimates by ethnic group and country of birth. Population Trends 1990; 59: 35-8

13 Probert CSJ, Jayanthi V, Pinder D, Wicks ACB, Mayberry JF. Epidemiological study of ulcerative proctocolitis in Indian migrants and the indigenous population of Leicestershire. Gut 1992; 33: 687-93.

14 Jayanthi V, Probert CSJ, Pinder D, Wicks ACB, Mayberry JF Epidemiology of Crohn's disease in Indian migrants and indigenous population of Leicestershire. Qf Med 1992; 82: 125-39.

15 Probert CSJ, Jayanthi V, Wicks ACB, Mayberry JF. Mortality of ulcerative colitis in Leicestershire, 1972-1989. An epidemiological study. Dig $D$ is $S c i$ (in press).

16 Probert CS J, Jayanthi V Wicks ACB Mayberry JF Mortality among patients with Crohn's disease in Leicestershire. Gut 1992; 33: 1226-8.

17 Lennard-Jones JE. Classification of inflammatory bowel disease. Scand f Gastroenterol 1989; 24 (Suppl 170): 2-15.
18 Devlin HB, Datta D, Dellipiani AW. The incidence and prevalence of inflammatory bowel disease in North Tees Health District. World f Surg 1980; 4: 183-93.

19 Findlay JM, Jayartne SD. Chronic inflammatory bowel disease in the Asian community in Bradford. In: McConnell $R$ Rozen P, Langman MJS, Gilat T, eds. The genetics and epidemiology of inflammatory bowel disease. Basel: Karger, 1986: $124-8$

20 Gardner MJ, Altman DG. Calculating confidence intervals for proportions and their differences. Statistics with confidence. London: BMJ, 1989: 28-9.

21 Katz D, Baptista J, Azen SP, Pike MC. Obtaining confidence intervals for the risk ratio in cohort studies. Biometrics 1978 34: 469-74.

22 Gardner MJ, Altman DG. Calculating confidence intervals for relative risks, odds ratios, and standardised ratio and rates. Statistics with confidence. London: BMJ, 1989 $50-63$.

23 Bailey BJR. Confidence limits to the risk ratio. Biometrics 1987 43: 201-5.

24 Binder V, Roth H, Hansen PK, Hendriken C, Kreiner S, Torp-Pedersen $\mathrm{K}$. Incidence and prevalence of ulcerative colitis and Crohn's disease in the County of Copenhagen 1962-1978. Gastroenterology 1982; 83: 563-8.

25 Jones HW, Grogono J, Hoare AM. An audit of ulcerative colitis in a district hospital. Gut 1985; 26: A1123.

26 Daiss W, Scheurlen M, Malchow H. Epidemiology of inflammatory bowel disease in the County of Tübingen (West Germany). Scand F Gastroenterol 1989; 224 (Suppl 170): 39 43.

27 Fellows IW, Freeman JG, Holmes GKT. Crohn's disease in the City of Derby. Gut 1990; 31: 1262-5.

28 Evans JG, Acheson ED. An epidemiological study of ulcerative colitis and regional enteritis in the Oxford area. Gut 1965; 6 : $311-24$

29 Miller DS, Keighley AC, Langman MJS. Changing patterns in epidemiology of Crohn's disease. Lancet 1974; ii: 691-3.

30 Sherlock P, Bell BM, Steinberg H, Almy TP. Familial occurrence of regional enteritis and ulcerative colitis. Gastroenterology 1963; 45: 413-20.

31 Kirsner JB, Spence JA. Familial occurrence of ulcerative colitis, regional enteritis and ileocolitis. Ann Intern Med colitis, regional

32 Almy TP, Sherlock $P$. Genetic aspects of ulcerative colitis and regional enteritis. Gastroenterology 1966; 51: 757-63. 